\title{
Design of Web-Based Cashier and Spare Part Warehouse Application Display (Case Study at Surya Motor Shop)
}

\author{
Muhammad Esa Permana Putra ${ }^{1}$, Teguh Bharata Adji ${ }^{*}$, Adhistya Erna Permanasari ${ }^{3}$
}

\begin{abstract}
A cashier and spare parts warehouse application is an information system facilitating financial reporting and items inventory systems. This has become a necessity in almost all fields of large and small-scale businesses in every country. The information system that belongs to Surya Motor Shop does not have a display that can facilitate users in operating the company's financial and transaction systems in accordance with company needs. This information system uses Bootstrap with HTML, CSS, and Javascript programming languages. In this paper, an interactive display was developed, so as to be able to accommodate web users' responses, by developing a prototype using Bootstrap at the Surya Motor Shop. This was carried out to digitize the transaction system, making it easier to report the items inventory and financial reporting of the company. The prototype development was developed using the The Elements of User Experience method, a user-centered design process. After developing the prototype, a test was carried out to determine the quality of the user experience. The test employed the User Experience Questionnaire (UEQ) method. UEQ testing shown that the prototype interface developed had a positive level of user experience. Compared with the benchmarks set by UEQ, the test results were above the mean benchmark, except for the pull factor which was still below the benchmark average.
\end{abstract}

Keywords - Cashier and Warehouse Information Systems, User Experience, The Elements of User Experience, User Experience Questionnaire.

\section{INTRODUCTION}

Nowadays information technology is developing very fast, so it becomes a mainstay and a need for both the community, organizations, and companies. With information technology, many parties obtain physical and non-physical benefits.

A web application is an application accessed using a web browser via a network such as the internet. A web application is also a computer software application coded in a language supported by web browsers, such as HTML, CSS, Javascript, and PHP, and relies on the browser to display the application.

Almost all large and small-scale business actors in all countries in the world have created and utilized web applications with various function types, according to business needs, such as Amazon.com, WhatsApp, Instagram, LinkedIn, and others. This also happens in Indonesia which has thousands of business actors who have so many needs from their respective businesses. Therefore, a web application was

1,2,3 Department of Electrical and Information Engineering, Faculty of Engineering, Universitas Gadjah Mada, Jln. Grafika 2, Kampus UGM Yogyakarta 55281 INDONESIA (e-mail: ${ }^{2}$ adji@ugm.ac.id, 3 adhistya@ugm.ac.id) developed to accomodate the needs of one of small-scale business operators in Indonesia, namely Surya Motor Shop.

The developed web application is an application adapting one of the business needs in Indonesia, namely the cashier and warehouse application. Each user can calculate and report financial transactions and report the items inventory. In this application, there are also features and its users can create a flow of financial transactions and the items inventory involving an admin to set the numbers of items and the amount of money that goes in and out every month.

At this time, that web application is still under development. One component in the development stage and applied to the system is a web application interface. With this component, it is expected that the system can display features that do not yet have interfaces. Within these components, an interface is necessary to facilitate web applications use in task operation in the web application.

Interface is a communication mechanism between users and a system. The interface can receive information from the user and provide information to the user to help directing problem investigation until a solution is discovered. There are several frameworks that can be used to develop web application interface such as Bootstrap, Foundation, Skeleton, and others. Bootstrap is one of the interface development frameworks in web applications currently the most widely used open source. Bootstrap also looks lighter and has complete documentation, making it easier for developers to learn it. Therefore, this Bootstrap framework is better known than the others and is very supportive in developing the web applications interface.

Based on these problems, in this paper an interface was designed using Bootstrap framework on the cashier web application and inventory items. In this web application, an attractive interface was needed to support the performance of the system being built.

This paper aims to produce a display system that can facilitate the user in operating a transaction system, making it easier to report items inventory and corporate finance in accordance with the user's preference. This display uses Bootstrap with the programming languages HTML, CSS, and JavaScript. This display is interactive, which means it has the ability to accommodate web application user responses.

Some advantages of conducting prototype development for cashier and spare parts warehouse information system are the cashier and spare parts warehouse features make it easy to directly report the item numbers and finance. Therefore, users can also find out about store income and find items available in store warehouses. This paper describes the product developing process using The Elements of User Experience and the product 
evaluating process using the User Experience Questionnaire (UEQ) as well as being a reference for further researches aiming to discuss the cashier application and spare parts warehouse interfaces.

\section{LITERATURE REVIEW}

\section{A. Cashier and Warehouse Information System}

A previous study about the items stock at PT. Wings Surya in Pacitan district explains that currently the need for computers is increasing rapidly [1]. With its accuracy, computers are increasingly being used in various applications. PT. Wings Surya is a distribution company that does not yet have a sophisticated, effective and efficient information system. The purpose of this study was to produce items stock information system at PT. Wings Surya in Pacitan. With the creation of a computerized information system and database, users are expected to be able to use it in the process of managing stock and to produce the right information at this company [1].

Another study describes the adoption of new systems or improvements to systems made on existing databases and networks [2]. If the application of a new system to the cash register requires a new or modified database and network, then this new system usually has to be implemented before installing a computer program.

The second stage was creating and testing a program. This stage was the first stage for a system development cycle specific to the programmer. This second stage aimed to develop more detailed plans for developing and testing new computer programs or an old-computer-repairing-program and for developing computer programs that accurately met the business processing needs [2]. In the third stage, the software package was installed and tested. This stage was carried out to ensure that new system integration needs were met. A conversion plan was also developed at this stage so that the delivery of the new system into operation could run successfully.

In the last stage, a delivery of a new system into operation was carried out [2]. The purpose of this stage was to gradually change the old system (conventional) into a new system (computerized). Therefore, it was necessary to install a database that would be utilized on the new system, to provide training and documentation for individuals who would use the new system, and to do a project and system evaluation.

However, from these studies, none of them has discussed the development of cashier and warehouse information systems based on user experience knowledge and user-centered design approaches [2].

\section{B. Evaluation Using the User Experience Questionnaire (UEQ)}

Questionnaires are tools that can be used to measure the user's experience values of a product. One of the questionnaires often used in the field of user experience is UEQ. In a study, observations were made on the field of user experience in the information technology industry in Denmark [3]. This observation was carried out by conducting a survey of several information technology companies. Although it is not the most popular among academics, the research shows that UEQ is the most popular evaluation method in the information technology industry.

Other studies discused the user experience evaluation in elearning environments [4]. In this study, a learning management system called Student Centered e-Learning Environment (SCELE) was used as the evaluated product. SCELE testing involved the participation of 213 students of the Computer Science Department. SCELE test results showed that the UEQ values for pragmatic aspects (perspicuity, efficiency and dependability) were good, while for the hedonic (stimulation and novelty) aspects were neutral. This study also discussed the development of Indonesian version UEQ in order to facilitate Indonesian-language participants in understanding UEQ questions.

In addition, a system utilizing gaze as an interaction medium of an interface has been developed [5]. In this research, UEQ was used as one method to evaluate user experience systems that had been developed. The evaluation results using UEQ showed that the efficiency aspect was average, while the other aspects were positive. Whereas in [6] the user experience evaluation of the StudiVZ site, a social platform for students in Germany, was discussed. This study aimed to find factors that could influence user interest in a social software. The evaluation utilized the UEQ method and this was administered online involving 722 participants. The results indicated that the stimulation factor, an UEQ hedonic quality, had the most influence on the level of interest in the StudiVZ user interface. This influence was directly proportional with the platform use intensity, therefore it could be concluded that careful consideration of the hedonic quality was very useful in providing influence, both in the short term and long-term influences.

\section{METHODS}

\section{A. Process of the Elements of User Experience}

The Elements of User Experience is a user-centered design concept that helps the process of developing user experience by dividing and mapping the design into five areas [7]. The five fields are strategy, scope, structure, skeleton, and surface, which will be explained as follows.

1) Strategy Development: The first process in The Elements of User Experience was a strategy development. It is stated that the strategy field is a direction determinant of a product development [8]. The results of the strategy development are divided into two discussion parts, namely product objectives and user needs.

Product objectives are goals determined by researchers. In this case, the objectives of the cashier information system and spareparts warehouse are closely related to user needs. The product objectives that have been set are as follows.

1. Providing effective search for item lists.

2. Speeding up the search for detailed income information.

3. Observing the whole transaction more clearly.

4. Simplifying the process of item inputs.

5. Providing cashier application in the system. 


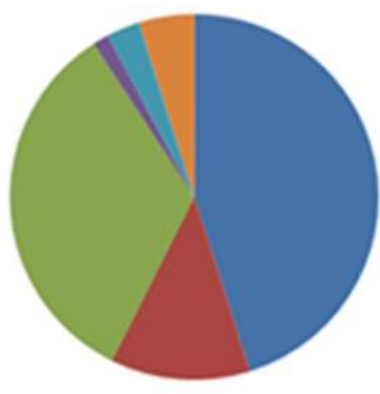

45.1\% Calculation assistance

12.3\% Invoice

33.4\% Item number

1.4\% All transaction

$2.9 \%$ Items input

$4.9 \%$ Net income and gross revenue

Fig. 1 Results of the core functions selection.

TABLE I

EXAMPLE OF QUESTIONNAIRE RESULTS

\begin{tabular}{|l|c|c|}
\hline $\begin{array}{c}\text { Users Who Recognize the Exact } \\
\text { Item Numbers in the Spare Parts } \\
\text { Warehouse }\end{array}$ & \multicolumn{2}{|c|}{ Total } \\
\hline Recognize & 5 & $25 \%$ \\
\hline Do not recognize & 15 & $75 \%$ \\
\hline
\end{tabular}

User needs come from an understanding of the desires of people willing to use this information system. In order to know the users' needs, user research was carried out in the form of questionnaires and direct discussions with users. The activity was carried out for three days at the Surya Motor Shop. The questionnaires distribution involved twenty respondents. One questionnaire result is shown in Table I.

In the questionnaire, participants were also given a list of some functions that could be applied in a cashier information system and spare parts warehouse. Participants were asked to provide opinions by choosing a maximum of two functions that must be present in a cashier information system and spareparts warehouse. This was useful as a consideration in determining core functions given top priority to be actualized in the prototypes development. The results of the core functions selection are shown in Fig. 1.

2) Scope Development: The following is the scope development process. In the scope development, an abstract strategy field was technically elaborated in the preparation of function specifications and content requirements. Component of functional specifications is a detailed description about the developed product functions. Whereas content requirements are descriptions of the various types of required contents. Functions and content that had been determined in the development of this stage were sorted and arranged in the next field development [8].

Based on the strategy development results, the functions that would present in the end products could be determined. The functions are as follows.

1. Related to providing the cashier application:

a) the function of providing calculation assistance, and

b) the function of providing spare part sales invoices.

2. Related to providing information on items:

a) the function of providing information on the items total number, and b) the function of providing information on the sold item numbers.

3. Related to providing financial information:

a) the function of providing information on all transactions,

b) the function of providing information on all gross income, and

c) the function of providing information on all net income.

The required contents were formulated based on the strategy development results. Determination of these requirements was fully determined by considering the user research results in the previous field development.

3) Structure Development: In the structure development, functions and content that had been determined in the scope field were sorted and arranged. The function was assembled by developing an interaction design in order to show the way an information system behaved in response to users. While the content was arranged into an information architecture, a content grouping that would facilitate the users' understanding when accessing the cashier's information system and store warehouse [8].

Information architecture is the structural design of all information and content of a product. The process of assembling an information architecture involved a card sorting method. Card sorting was carried out to obtain the user's point of view in content grouping [8]. The types of utilized card sorting were the open card sorting and the closed card sorting [9]-[11].

4) Skeleton Development: The skeleton section can be divided into three parts. Both in terms of function and content, it is necessary to have an information design component. Information design is an information representation that can assist user's understanding. In addition to information design, there are also interface design components and navigation design.

5) Surface Development: The last field is the surface. In this field, what would be developed was the sensory experience [8]. The development and discussion of sensory experiences can be represented by a prototype. At this stage, a prototype of the final product was developed. The development of prototype interfaces utilized desktop-web platforms. The desktop-web 


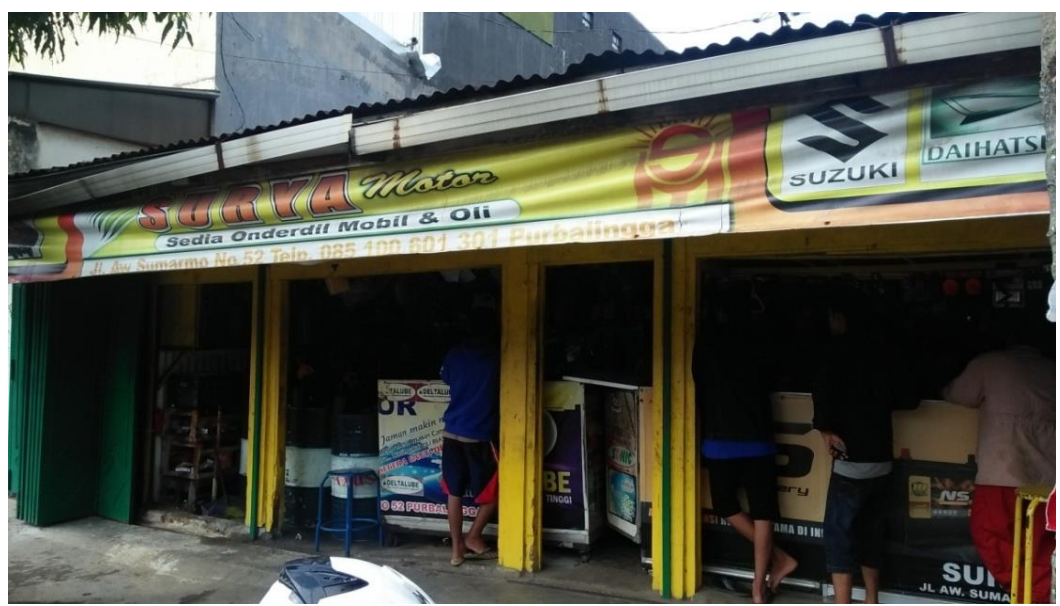

Fig. 2 Surya Motor Shop.
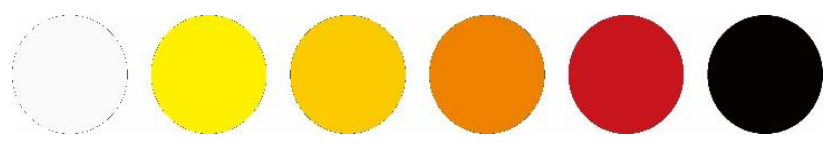

Fig. 3 Color palettes.

platform was utilized to facilitate users in accessing prototypes. The development of desktop-web prototypes utilized the web technology HTML, CSS and Javascript.

In the surface development, a prototype was generated. The prototype was developed using a desktop-web platform. The desktop-web platform was used to be easily accessed and could be observed clearly.

The prototype was an information system user interface. The user interface components were developed based on the wireframe generated in the skeleton development. As for the color selection, a yellow palette with a dark contrast theme was selected. This color selection was based on the Surya Motor Shop branding color, as shown in Fig. 2.

The dominant yellow color was used to avoid using too many colors without any clear purpose for use. Applying too much color in an interface could result in reduced productivity and could obscure information. The color palette is shown in Fig. 3.

Given the fact that the predetermined platform for prototyping was desktop-web, the development process utilized HTML, CSS and Javascript web technology. The data utilized by the prototype was not actual data, therefore the prototype did not use a database and did not need to be processed from the server.

The prototype that had been developed consisted of several pages, namely 'Aplikasi Kasir', 'Gudang Spareparts', 'Input Barang', 'Daftar Barang', 'Pendapatan Bersih', 'Pendapatan Kotor', and 'Transaksi Keseluruhan'.

The information system main page consisted of two pages, namely 'Aplikasi Kasir' and 'Gudang Spareparts'. Navigation between the two pages was administered using the button component. From the 'Aplikasi Kasir' page the user could see a list of purchased items, then they would be redirected to the 'Selesai' page. Users would be given complete information regarding the purchase invoice.
The 'Gudang Spareparts' page displayed options to the next page, namely 'Jumlah Barang' and 'Input Barang'. On the 'Jumlah Barang' page, a list of all items in the Surya Motor shop warehouse was displayed. Meanwhile, the 'Input Barang' page displayed a page providing a place to put items into the warehouse. Both of these pages were provided for experienced users in the warehouse section, so they could directly search for or input items on the 'Jumlah Barang' or 'Item Input' pages.

The 'Admin' page provided information about the entire Surya Motor Shop's transaction. In addition to providing detailed information about transactions, the 'Admin' page also displayed information content related to gross revenue and net income. The 'Pendapatan Kotor' page provided information on store income per day, month and year. Just much the same as 'Pendapatan Kotor', the 'Pendapatan Bersih' page also displayed information content related to store net revenue. The cashier application page display is shown in Fig. 4.

\section{B. Evaluation Results of User Experience Questionnaire (UEQ)}

User experience evaluation on the interface prototype of the developed cashier and spare parts warehouse information systems has been carried out using UEQ method. In order to obtain a large number of samples, the evaluation of user experience was carried out online. This evaluation involved twenty randomly selected respondents.

The process of selecting participants was done by randomly selected names from a list of names that had been prepared. Evaluation forms were distributed to selected participants and they were asked to distribute evaluation forms to other users, so that the forms were distributed to twenty respondents. The evaluation process was carried out online by participants.

First, participants were directed to a Google Forms site page containing user experience evaluation material, including UEQ forms. Then, participants were divided based on experience in the cashier and experience in the warehouse. Once divided, participants were given a task needed be done using a prototype cashier information system or spareparts warehouse. The tasks to be performed by users varied according to the user type. 


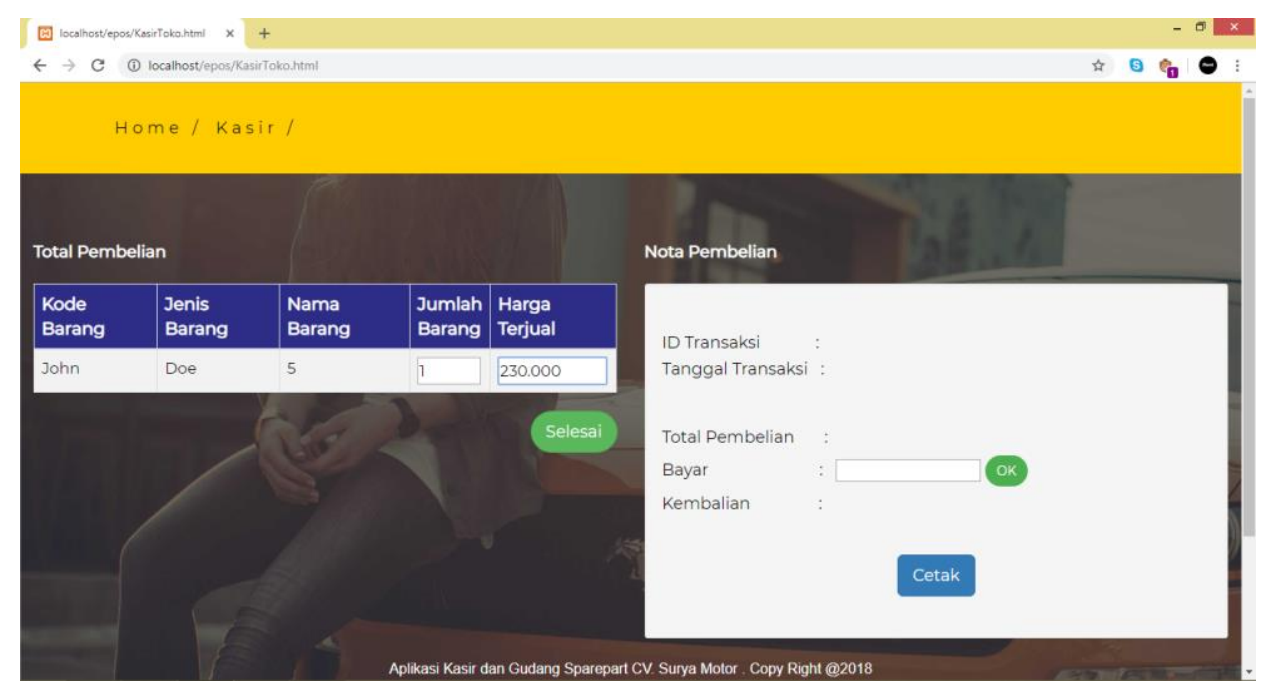

Fig. 4 Cashier application page display.

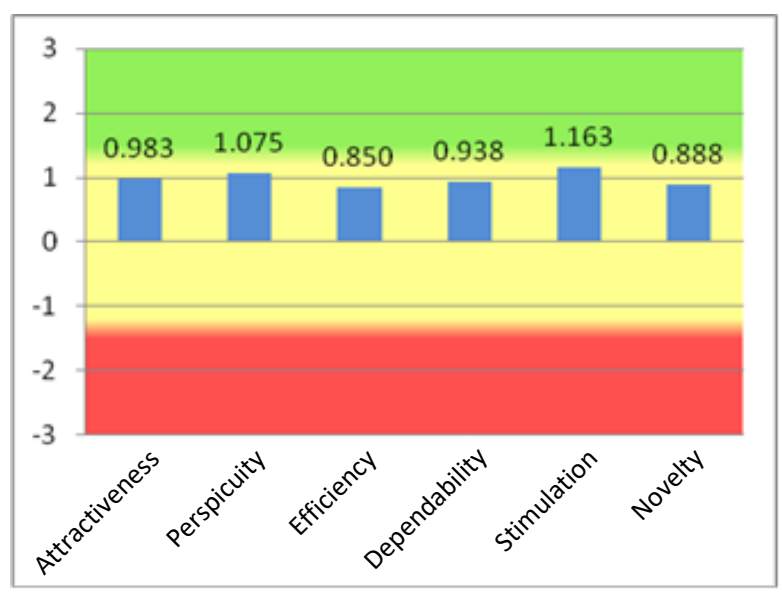

Fig. 5 Graph of UEQ test results.

After carrying out all the instructions given, participants were given a UEQ form to fill out. After completing the UEQ form, participants were also given the opportunity to submit suggestions or criticisms.

From the UEQ testing results of all participants, it can be seen that the average value of the six factors respectively is 0.983 for attractiveness, 1.020 for perspicuity, 0.850 for efficiency, 0.938 for dependability, 1.163 for stimulation, and 1.183 for novelty. These results are between a scale of 3 (very good) and -3 (very bad). The test result values for all UEQ factors can already be considered positive because they are above 0.8 [4]. The results in graphic form are shown in Fig. 5.

The reliability of UEQ can also be said to be good. This can be noticed from Cronbach's alpha coefficient value for each UEQ factor. The alpha coefficient values of each UEQ factor are 0.74 for attractiveness, 0.80 for clarity, 0.79 for efficiency, 0.74 for accuracy, 0.64 for stimulation, and 0.85 for novelty. Only alpha coefficient values for stimulation factors are less than 0.7 . This can be caused by poor product quality and unattractive features.

UEQ test results were also compared with benchmarks that had been determined by UEQ. Compared with the UEQ benchmark, each factor of the test results was already above the benchmark average, except the stimulation factor which was below average. A comparison of test results with UEQ benchmarks is shown in Fig. 6 at the end of the paper.

\section{CONCLUSIONS}

This paper aims to develop a prototype of a cashier information system and spare parts warehouse based on user experience and to evaluate the user experience prototype that has been developed. This was based on the problem formulation that there was no research on the development of cashier information systems and spare parts warehouse based on user experience knowledge. This paper has successfully developed a prototype using the The Elements of User Experience method and evaluated the developed prototype using the UEQ method. From the test results, several conclusions can be drawn as follows. The development of a prototype of the cashier information system interface and spare parts warehouse could be carried out using the The Elements of User Experience method, a user-centered design process including five stages of development, namely strategy, scope, structure, skeleteon and surface. Additionally, user experience test of of the cashier information system interface and spareparts warehouse using UEQ showed positive evaluation results with the value of each factor being 0.933 for attractiveness, 1.188 for perspicuity, 1.138 for efficiency, 1.312 for dependability, 1.175 for stimulation , and 1.150 for novelty. Finally, the results of testing the clarity, efficiency, accuracy, stimulation and novelty factors were above the UEQ benchmark average, while the attractiveness factor was below the benchmark average.

\section{REFERENCES}

[1] A.R.M. Suci and I.U. Wardati, "Pembuatan Sistem Informasi Pengelolaan Stok Barang pada Perseroan Terbatas Wings Surya di Pacitan," SeruniSeminar Riset Unggulan Nasional Informatika dan Komputer, Vol. 1, No. 1, 2012.

[2] R.B. Bukit, "Penelitian Implementasi Sistem Informasi: Pendekatan yang Lebih Integratif," Universitas Sumatera Utara, Medan, Indonesia, Lecture papers, 2002 


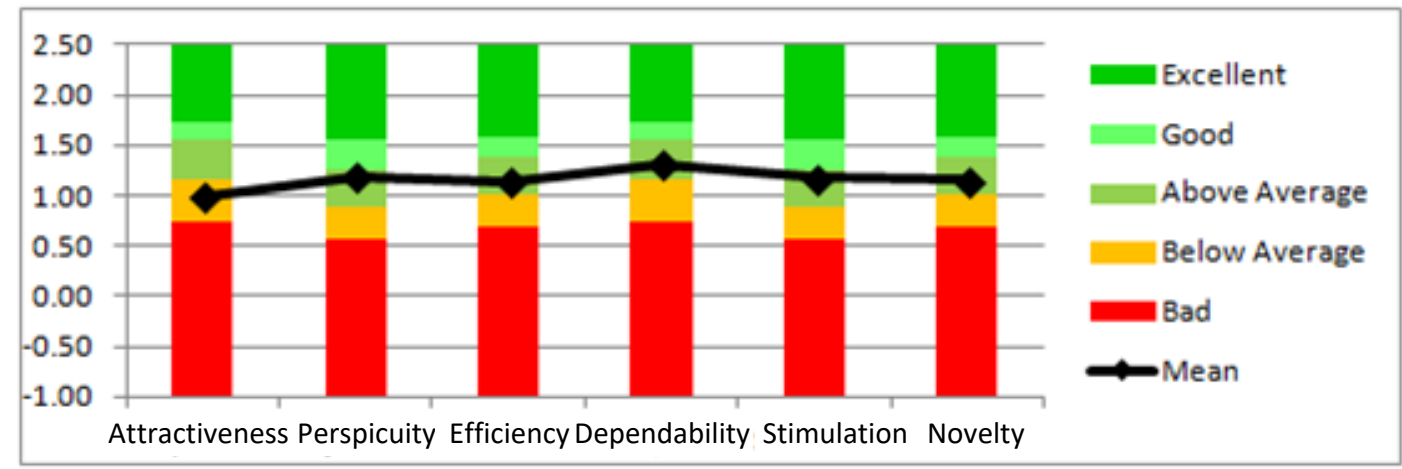

Fig. 6 Comparison of test results with UEQ benchmarks.

[3] K. Bang, M.A. Kanstrup, and A. Kjems, "UX Evaluation Methods: An Investigation of the Danish IT-Industry's Work and the Relevance of Literature," Master thesis, Aalborg University, Aalborg, Denmark, 2015.

[4] H.B. Santoso, M. Schrepp, R.Y.K. Isal, Y. Utomo, and B. Priyogi, "Measuring User Experience of the Student-Centered e-Learning Environment," J. Educ. Online-JEO, Vol. 13, No. 1, pp. 142-166, 2016.

[5] D.H. Cymek, A.C. Venjakob, S. Ruff, O.H. Lutz, S. Hofmann, and M Roetting, "Entering PIN Codes by Smooth Pursuit Eye Movements," Journal of Eye Movement Research, Vol. 7, No. 4, pp. 1-11, 1982.

[6] W. Ilmberger, M. Schrepp, and T. Held, "Attractiveness of Social Platforms: An Investigation of StudivZ," Proc. IADIS Int. Conf. Interfaces Hum. Comput. Interact., 2011, pp. 257-264.
[7] J. Nielsen (2004) "Card Sorting: How Many Users to Test," [Online], https://www.nngroup.com/articles/card-sorting-how-many-users-to-test/, access date: 18-Jun-2016.

[8] J.J. Garrett, The Elements of User Experience: User-centered Design for the Web and Beyond, London, UK: Pearson Education, 2010.

[9] D. Spencer and J.J. Garrett, Card Sorting: Designing Usable Categories, New York, USA: Rosenfeld Media, 2009.

[10] T. Tullis and W. Albert, Measuring the User Experience - Collecting, Analyzing, and Presenting Usability Metrics, $2^{\text {nd }}$ ed., San Francisco, USA: Morgan Kaufmann Publishers Inc., 2013.

[11] A. Nawaz, "A Comparison of Card-sorting Analysis Methods," 10th Asia Pacific Conf. Comput. Hum. Interact., 2012, pp. 1-10. 